\title{
VIABILIDADE ECONÔMICA DE REDES DE DISTRIBUIÇÃO PROTEGIDAS
}

\author{
Mário Lúcio de Sales Brito ${ }^{1}$, Pedro Mendes Castro ${ }^{2}$
}

O objetivo deste estudo é demonstrar que a utilização generalizada das Redes Protegidas é viável em todas situações encontradas nos meios urbanos.

A análise econômica considera além do investimento inicial, os custos operacionais, comparando-os aos de outras modalidades de redes.

Pela simplicidade de suas instalações básicas, observa-se que este método compete em custo e vantagens em relação a alternativas, como as redes aéreas isoladas, podendose independentemente das condições e importância do local e da densidade de carga, utilizar esta modalidade de rede.
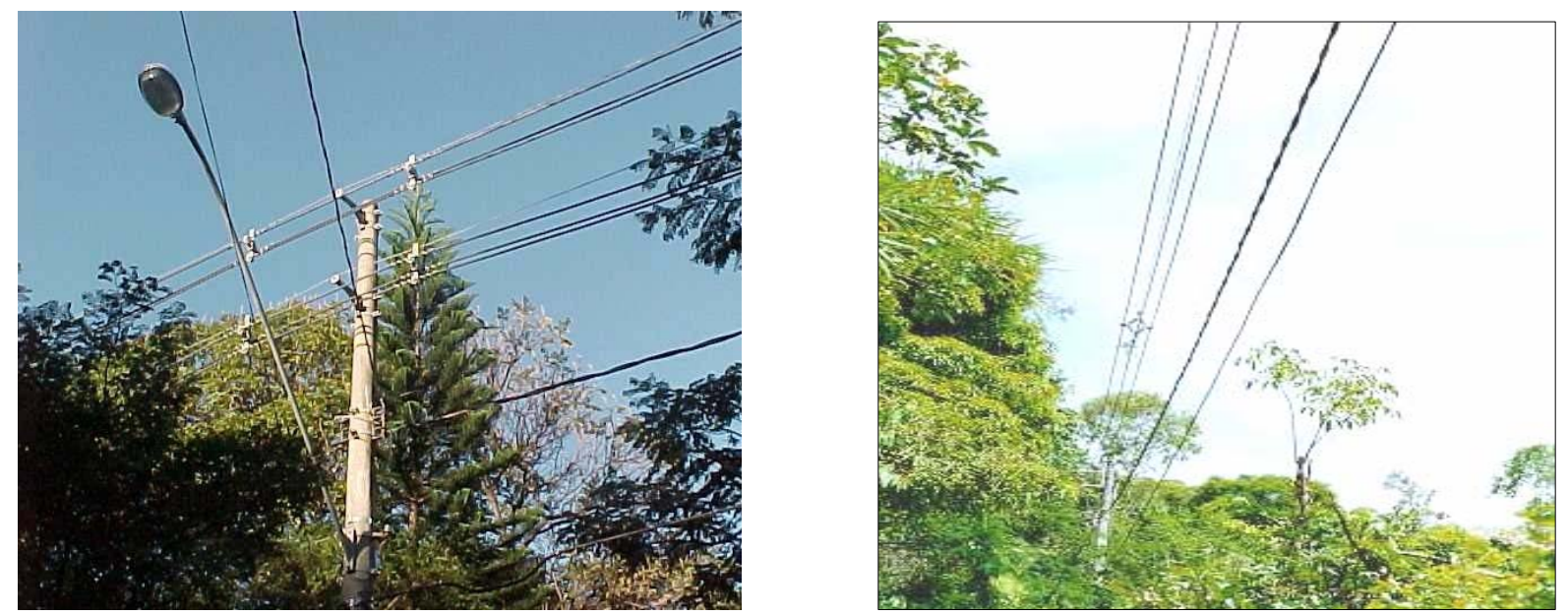

Do ponto de vista técnico, sua aplicação em redes urbanas proporciona:

- Redução drástica na taxa de falhas, com conseqüente redução das intervenções na rede;

- Redução substancial na duração e freqüência dos desligamentos;

- Minimização das manutenções, liberando eletricistas para outros serviços;

- Aumento da segurança para os eletricistas e público em geral;

- Redução da em freqüência e intensidade das podas de árvores;

- Melhoria da imagem da Empresa junto a prefeituras, entidades de proteção/defesa ambiental e consumidores de uma forma geral.

\footnotetext{
1 Engenheiro, Gerência de Engenharia e Coordenação da Expansão da Distribuição - CEMIG, mbrito@cemig.com.br

Engenheiro Agrônomo, Gerencia de Engenharia e Coordenação da Manutenção - CEMIG, pedro@cemig.com.br
} 
Os tipos de redes em análise correspondem às seguintes nomenclaturas:

- $\quad$ RDA - Rede de Distribuição Aérea Urbana é constituída de rede primária e secundária com cabos alumínio nus, média tensão (MT) sobre cruzeta de madeira e isoladores de vidro/porcelana, baixa tensão (BT) em disposição vertical e equipamentos, lluminação Pública (IP), Ramal de Ligação (RL) e medição convencionais.

- $\quad$ RSI - Rede Secundária Isolada é composta de rede primária com cabos alumínio (CA) nus sobre cruzeta de madeira e isoladores de vidro/porcelana, secundária com cabos isolados multiplexados de BT e, equipamentos, IP e RL/medição convencionais.

- $\quad$ RDP - Rede de Distribuição Aérea Protegida, é constituída de rede primária com cabos cobertos em espaçadores e isoladores poliméricos, secundária com cabos isolados multiplexados de BT, transformador auto protegido, chave SF6 e demais equipamentos, IP e $\mathrm{RL} /$ medição convencionais.

\section{Análise da Viabilidade Econômica das Redes Protegidas}

\section{Considerações Gerais}

A análise econômica das Redes Protegidas determina valores que possibilitam estabelecer comparações entre outras modalidades de redes quanto aos seus custos.

Os Custos Totais, que representam os custos sob o enfoque exclusivo da CEMIG, são determinados admitindo-se a incidência periódica dos seguintes eventos geradores de custo, ao longo da vida útil esperada para as redes:

- Necessidade de investimento inicial diferenciado;

- Aplicação de manutenções periódicas corretivas e preventivas (custos operacionais);

Com relação ao horizonte de estudo, é adotado o período de 25 anos para todas as modalidades de rede, como sendo a vida útil de uma rede aérea de distribuição com posteação de concreto/madeira.

Para efeito de análise, todos os custos estão expressos em valores anuais, em dólares / estrutura de rede (valor do Dólar US\$1.00 = R \$2,10 em fev/07).

\section{Determinação dos Investimentos Iniciais}

Os investimentos iniciais correspondem aos orçamentos obtidos junto às Gerências Regionais da Cemig, para cada modalidade de rede, nas obras de extensão / modificação e reforma / melhoramento. 
Para efeito deste trabalho, foram considerados os seguintes investimentos, por representarem a média dos projetos reais executados pelas regionais:

\begin{tabular}{|c|c|c|c|}
\hline Investimento Inicial (US\$/poste) & RDA & RSI & RDP \\
\hline Obra de Extensão / Modificação & $1.730,00(98 \%)$ & $1.763,00(100 \%)$ & $1.983,00(112,5 \%)$ \\
\hline
\end{tabular}

Para efeito de análise comparativa entre os valores encontrados, a RSI foi considerada como referência, em função da rede secundária isolada (com cabos multiplexados) já ser adotada pela CEMIG como seu padrão mínimo desde janeiro/1997.

Comparando-se os investimentos necessários para cada modalidade de rede, verifica-se que a RDP requer um investimento inicial superior em $12,5 \%$ para as obras de extensão.

Entretanto, esta diferença é compensada pelos custos operacionais capitalizados anualmente.

\section{Determinação dos Custos Operacionais}

Os custos operacionais anuais por estrutura podem ser decompostos em duas parcelas, correspondentes a:

- Manutenções preventivas (Mp), realizadas por turmas de linha viva, linha morta e termovisão, visando preservar a integridade das instalações e manter a continuidade do fornecimento de energia;

- Manutenções corretivas (Mc), efetuadas pelas equipes de plantão, para restabelecer o sistema durante uma interrupção acidental.

\subsection{Manutenção preventiva}

A manutenção preventiva pode ser subdividida em duas parcelas:

- Manutenção geral das estruturas, condutores e equipamentos, especialmente a verificação de pontos quentes em conexões, chaves, fuga de corrente em isoladores, etc;

- Poda de árvores e retirada de objetos da rede.

O quadro a seguir apresenta os custos da manutenção preventiva para cada modalidade de rede, considerando locais arborizados ou não.

\begin{tabular}{|l|c|c|}
\hline \multicolumn{3}{|c|}{$\begin{array}{c}\text { Custo US\$/postelano } \\
\text { Manutenção Preventiva }\end{array}$} \\
\hline & Com Arborização & Sem Arborização \\
\hline RDA & $1.140,00$ & 550,00 \\
\hline RSI & 460,00 & 311,00 \\
\hline RDP & 180,00 & 58,00 \\
\hline
\end{tabular}


Observa-se que o custo da manutenção preventiva das redes convencionais cresce significativamente em relação Redes Protegidas (relação de 6/1 para locais arborizados e de 9/1 para aqueles sem presença de árvores junto às redes).

Esta diferença é explicada pela periodicidade dos serviços requeridos, como também pela produtividade alcançada pelas turmas de manutenção.

\subsection{Manutenção Corretiva}

A manutenção corretiva ocorre em função do número de interrupções acidentais e do tempo de restabelecimento da interrupção urbana e, invariavelmente, durante esta manutenção ocorrem substituições de materiais danificados, além das manobras necessárias para a execução dos serviços na rede.

Eventualmente, acontece o ressarcimento aos consumidores de seus aparelhos eletrodomésticos danificados, devido à ocorrência de uma falha na rede (falta de fase, tensões elevadas no neutro, problemas em conexões, poda, etc).

O Quadro abaixo apresenta os custos da manutenção corretiva para cada modalidade de rede. Os cálculos de cada uma das parcelas que compõe a manutenção corretiva (custo da turma de plantão, dos materiais substituídos, dos eletrodomésticos queimados e das manobras na rede).

\begin{tabular}{|l|c|}
\hline \multicolumn{2}{|c|}{$\begin{array}{c}\text { Custo US\$/postelano } \\
\text { Manutenção Corretiva }\end{array}$} \\
\hline RDA & 155,00 \\
\hline RSI & 79,00 \\
\hline RDP & 34,00 \\
\hline
\end{tabular}

Conforme pode ser observado, o custo da manutenção corretiva das redes convencionais corresponde a cinco vezes ao de uma Rede Protegida, em função do elevado número de interrupções acidentais verificadas nos circuitos primário e secundário nus, com reflexo direto na elevada taxa de queima de aparelhos eletrodomésticos. 


\section{Custo Global das Redes de Distribuição}

O custo global das redes com os respectivos investimentos iniciais e custos operacionais:

\begin{tabular}{|l|l|c|c|c|c|}
\hline \multicolumn{9}{|c|}{ Custo US\$/poste } \\
\hline \multirow{2}{*}{} & $\begin{array}{c}\text { Investimento } \\
\text { Inicial }\end{array}$ & $\begin{array}{c}\text { Manutenção } \\
\text { Preventiva }\end{array}$ & $\begin{array}{c}\text { Manutenção } \\
\text { Corretiva }\end{array}$ & Custo Global \\
\hline \multirow{2}{*}{ RDA } & Arborizado & $1.730,00$ & $1.135,00$ & 155,00 & $3.020,00(131 \%)$ \\
\cline { 2 - 2 } & Não Arborizado & $(98 \%)$ & 550,00 & & $2.435,00(113 \%)$ \\
\hline \multirow{2}{*}{ RSI } & Arborizado & $1.763,00$ & 460,00 & 79,00 & $2.302,00(100 \%)$ \\
\cline { 2 - 2 } & Não Arborizado & $(100 \%)$ & 311,00 & & $2.153,00(100 \%)$ \\
\hline \multirow{2}{*}{ RDP } & Arborizado & $1.983,00$ & 180,00 & \multirow{2}{*}{34,00} & $2.197,00(95 \%)$ \\
\cline { 2 - 2 } & Não Arborizado & $(112,5 \%)$ & 58,00 & & $2.075,00(96 \%)$ \\
\hline
\end{tabular}

Analisando os valores acima encontrados, para as obras de extensão / modificação, verifica-se que:

- A análise comprova que a RDA tornou-se uma rede muito pouco viável economicamente em função de seus altos custos operacionais;

- A relação entre os investimentos iniciais de uma RDP e uma RDA é igual a 1,15. Já seus custos totais apresentam uma relação inferior à unidade, igual a 0,85 para locais não arborizados e igual a 0,72 para locais arborizados.

- Independentemente do fato de existirem árvores ou não, a relação entre a RDP e a RSI mantêm-se em $87 \%$, pois os custos operacionais inerentes às duas redes crescem na mesma proporção;

- Os investimentos superiores efetuados tanto para a RSI quanto para a RDP em relação à RDA já são compensados apenas pela capitalização dos custos operacionais.

\section{Conclusões}

A adoção de sistemas aéreos protegidos (RDP) passa a desempenhar papel de fundamental importância para alcançar os objetivos descritos nesta análise, principalmente no atendimento a unidades consumidoras que não podem sofrer frequentes interrupções do fornecimento de energia, tais como hospitais, bancos, grandes hotéis, shopping centers, entre outros.

Outro aspecto a destacar com o uso das Redes Protegidas é o aumento da segurança para o público em geral. No Brasil, os acidentes no sistema elétrico envolvendo 
pessoal próprio e principalmente terceiros, atingem números expressivos que poderiam ser substancialmente minimizados.

A CEMIG padronizou as Redes de Distribuição Protegidas como atendimento minímo urbano em abril de 1999 e tem instalado (dez/06) em seu sistema elétrico de 15kV, cerca de $4.232 \mathrm{~km}$ desta modalidade de rede.

Quanto aos índices de interrupção, a RDP proporciona uma drástica redução na taxa de falhas (ocorrências/km/ano) da ordem de de 10 a 15 vezes em relação à uma RDA. Este benefício proporciona uma diminuição na duração do desligamento acidental em mais de 7 horas, pois além das interferências do meio ambiente serem minimizadas, as interrupções programadas serão também menos frequentes.

Além desses aspectos, merecem também ser destacadas as seguintes vantagens a serem obtidas com a implantação das RDP como padrão mínimo de atendimento urbano:

a) Ganho significativo no custo operacional dessas redes devido ao menor número de intervenções e conseqüentemente liberação dos eletricistas de manutenção/restauração para outras atividades;

b) Compactação da rede, possibilitando a instalação de até quatro circuitos na mesma estrutura, sem prejuízo das condições de operação das redes; conforme as fotos a seguir:
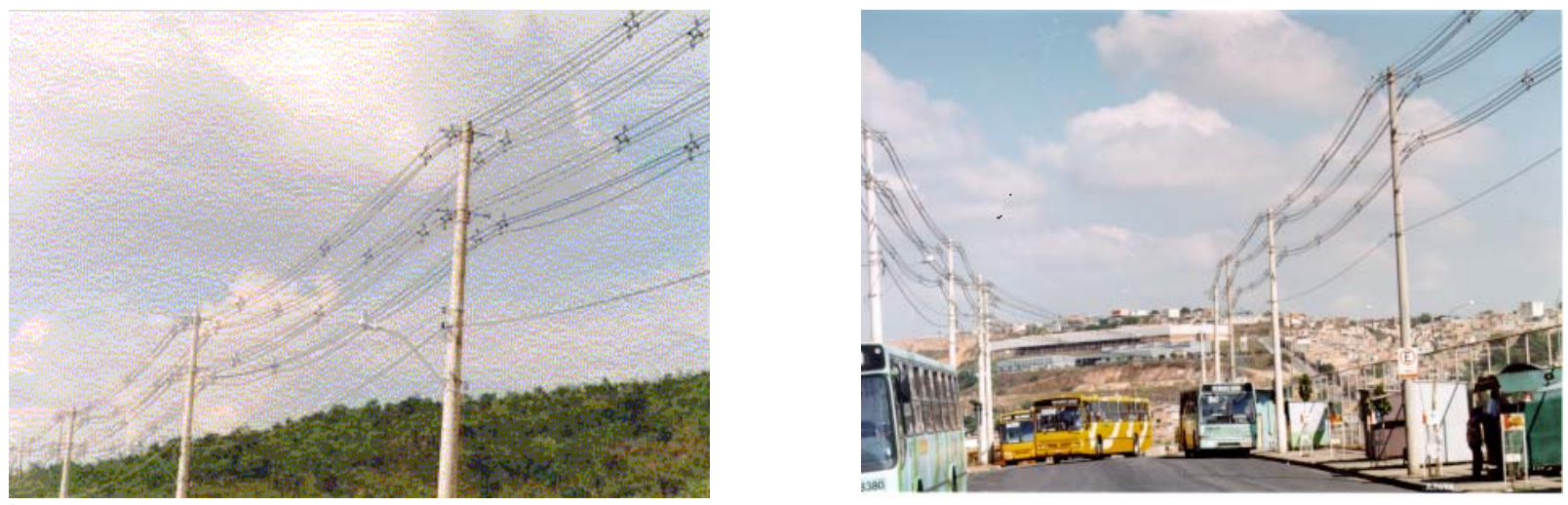

c) Com relação aos aspectos ambientais, face aos benefícios proporcionados por uma arborização preservada, refletida no clima e paisagem das cidades, as RDP's requerem podas bastante simples, correspondendo à retirada apenas de galhos que estiverem mecanicamente forçando os condutores, otimizando as podas de árvores e minimizando a freqüência e intensidade dos serviços, conforme ilustra a figura a seguir: 


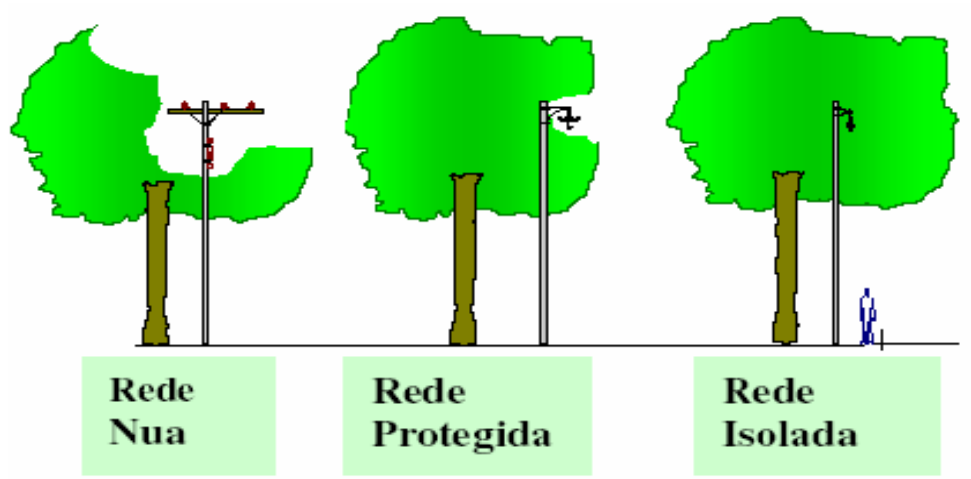

O uso dessa modalidade de rede, todavia, não elimina a necessidade poda nem o risco de interrupções no fornecimento de eletricidade devido à queda de árvores (ou parte delas) sobre os condutores. O contato permanente entre árvore e condutores proporciona uma corrente de fuga do condutor, e conseqüente desgaste do revestimento polimérico e perda de desempenho da rede, que passa a se comportar como uma rede nua. A reconstituição dos condutores, em caso de rompimento devido a queda de árvores sobre a rede, é muito mais complexo e demorado que em redes convencionais, o que acarreta maior tempo de restabelecimento e diminuição dos índices de desempenho dos sistemas, além da insatisfação dos consumidores.

d) Desenvolvimento do mercado fornecedor de materiais, gerando novas oportunidades de negócio, inclusive com instalação de unidades fabris como clientes da própria CEMIG;

e) Obtenção de economia de escala com conseqüente redução nos preços dos materiais específicos para a RDP, nas aquisições internacionais conduzidas pela Cemig, para o suprimento de quantidades significativas, correspondentes ao programa de obras da distribuição.

f) A análise evidencia que a RDA torna-se uma opção de rede inviável economicamente, em função de seus altos custos operacionais, em longo prazo;

g) Atualmente, o investimento inicial de uma RDP, é da ordem de $7 \%$ superior ao de uma RSI. O gráfico a seguir demonstra a evolução do custo para RDP e RSI de 1992 a 2006.

h) Aumento da competividade da CEMIG no novo mercado de energia, em função da

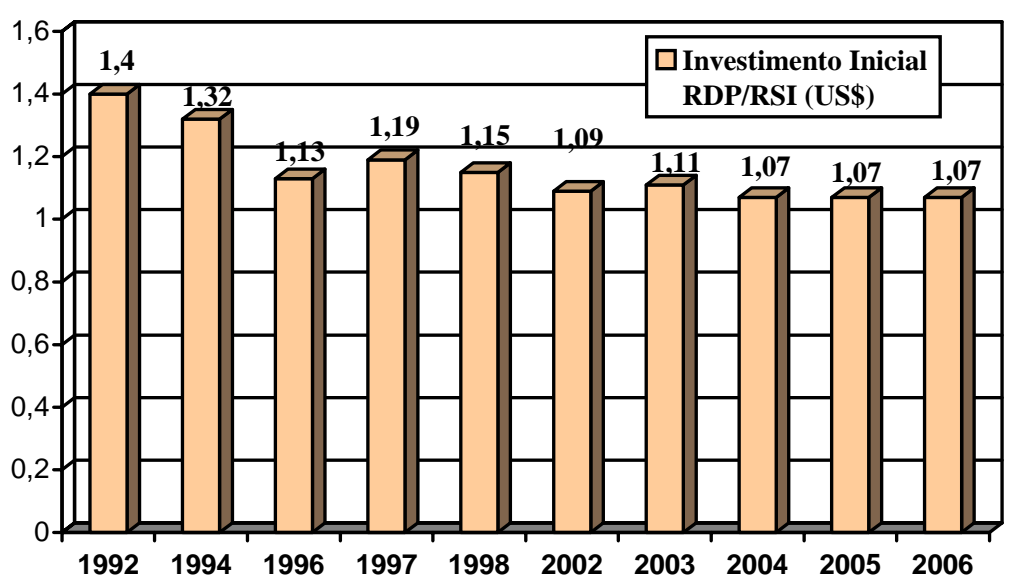


melhoria da qualidade do fornecimento (best power quality)

i) A RDP é sempre a opção mais econômica do que qualquer outra modalidade de rede, independentemente da complexidade da rede ou da existência de árvores, com um custo total de $87 \%$ em relação ao custo de uma RSI pode-se concluir que a RDP se paga em apenas 2,4 anos, vide a curva de Pay-Back:

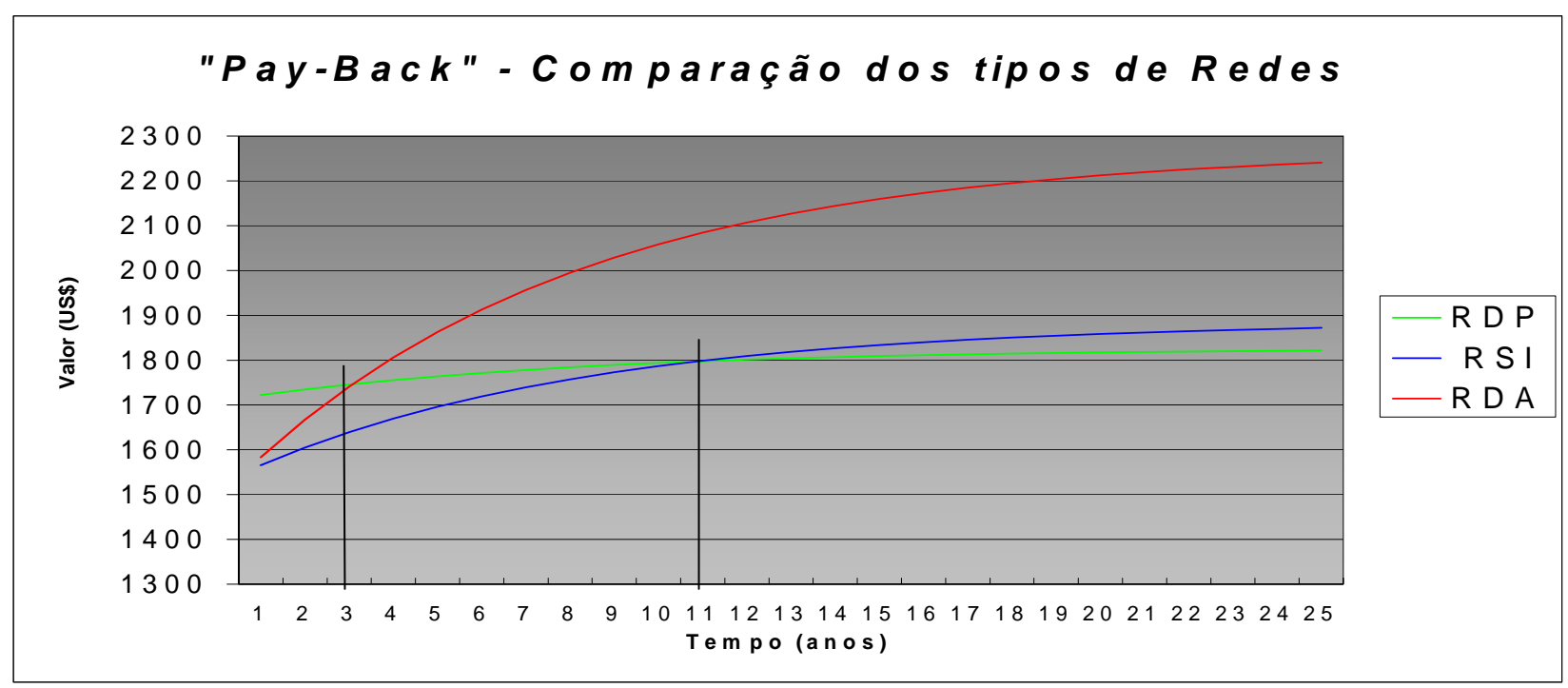

Com base nas análises realizadas pode-se dizer que as Redes de Distribuição Aéreas Protegidas de $15 \mathrm{kV}$ apresentam-se como sendo a melhor alternativa técnica e econômica para as redes.

Como a missão da Cemig é atuar no setor de energia com rentabilidade, qualidade e responsabilidade social, a escolha da RDP como padrão mínimo de atendimento urbano vem ao encontro desta diretriz empresarial. 